\title{
Research on the protection coordination of permanent magnet synchronous generator based wind farms with low voltage ride through capability
}

\author{
Renfeng Tao*, Fengting Li, Weiwei Chen, Yanfang Fan, Chenguang Liang and Yang Li
}

\begin{abstract}
To coordinate the protection of PMSG (permanent magnet synchronous generator), collector circuits and outgoing lines, a comprehensive and improved protection method of PMSG based wind farms with LVRT (low voltage ride through) capability is proposed. The proposed method includes adding a short time delay to the collector network current protection zone I and a directional protective relaying to the collector network protection, installing grounding transformers and zero sequence current protection, and generator low-voltage protection action improvement. A LVRT scheme consisting of variable resistance dumping circuit, grid side dynamic reactive power control and reactive power compensation control is proposed. The fault characteristics of PMSG based wind farms are analyzed, and a PMSG based wind farm in Dabancheng, Xinjiang, is used as an example to analyze typical wind farm protection configuration, the setting values considering LVRT requirements, and the coordination problems. Finally, an improved wind farm protection coordination methodology is proposed and its validity is verified by simulation.
\end{abstract}

Keywords: LVRT, Protection Coordination, PMSG, Wind Farm Fault Characteristics

\section{Introduction}

As a clean and renewable energy, wind power is developing rapidly in China. In 2015, the new wind power installed capacity has reached 30,753 MW, an increase of $32.6 \%$ compared to 2014 , and the total installed capacity has reached 145,362 MW, ranked first in the world.

Because of wind power's stochastic and variable operation nature, the stable operation of grid integrated with large scale of wind power and the protection configuration of wind farms are facing enormous challenges. Therefore, for maintaining the stability and safe operation of the power systems, wind turbines require to have the low voltage ride through capability [1-5]. Nevertheless, in the event of grid side fault or voltage dip, wind farms often simply trip to protect the wind turbines $[6,7]$. To solve the problem, many advanced LVRT technologies have been adopted by wind turbine manufacturers based on

\footnotetext{
*Correspondence: taorenfeng@126.com

College of Electrical Engineering of Xinjiang University, Xinjiang, China
}

GB19963(2011), including reducing input power of the wind turbine side converter by controlling the pitch angle or limiting wind turbine electric-magnetic power [8], eliminating the unbalanced power on the DC bus by installing power dumping circuit or energy storage devices [9], and enhancing grid-side converter output power by using var compensation devices, adding auxiliary converter, or adopting reactive power control strategy [10]. Though those measures can improve the LVRT capacity the wind turbine and wind farm fault characteristics can be changed [11], which potentially lead to misoperation and malfunction of their protection [12-14].

PMSG is an important type of wind power generator in China [15], and its market share has significantly increased in the last few years. For the protection coordination of PMSG, collector circuits and outgoing lines, this paper proposes a comprehensive and improved protection method of PMSG based wind farms with LVRT capability. The impact of various LVRT techniques on wind farm fault characteristics is considered. The rest of the paper is 
organized as follows. Section 2 analyzes and summarizes wind farm fault features and the research status on protection configuration. Section 3 proposes the LVRT scheme consisting of variable resistance dumping circuit, grid side dynamic reactive power control and reactive power compensation control, and analyzes the PMSG wind farm fault characteristics. In Section 4, a PMSG based wind farm in Dabancheng, Xinjiang, China is used as an example to analyze the typical wind farm protection configuration, its setting values considering LVRT requirements and its existing issues on the coordination among its protections. In Section 5, an improved wind farm protection coordination methodology is proposed and its validity is verified by simulation. Finally, conclusion and perspectives for future work are given in Section 6.

\section{Research status of wind farm protection}

\subsection{Research status of wind farm fault characteristics}

Existing researches have mainly focused on the criterion of fault current with little emphasis on fault characteristics of wind turbines (especially PMSG) with LVRT capability. Short circuit currents of different types of wind turbines show significant differences due to the different control strategies in [16-19], which can have a great impact on the protection setting. According to the flux balance equations and frequency-domain analysis, mathematical expressions of the short circuit current for doubly-fed induct generator (DFIG) are derived without considering the effect of the crowbar $[20,21]$. However, the short circuit current characteristics will be different when crowbar circuit is used in DFIG wind turbines [22, 23]. The PMSG short circuit current does not normally exceed the rated current of the grid side converter [24]. Control process of the full power converter that quickly isolates PMSG faults is analyzed in [25], and the short circuit current flowing into the grid is shown to be controllable. Therefore, the control strategy of LVRT of PMSG can affect the short circuit current characteristics, and the protection setting and configuration.

\subsection{Research status of wind farm protection configuration}

At present, most of the researches focus on the protection of the collector networks and outgoing lines of wind farms with little on protection and coordination of wind farms with LVRT capability. It has shown that wind farm integration and its fault current attenuation characteristics may reduce the reliability of current protection in power grids $[26,27]$. Thus, the setting of wind farm collector network instantaneous protection should not only consider its short circuit current characteristics, but also require installing directional element if necessary $[28,29]$. An adaptive protection method based on short circuit current characteristics is presented in [30,31], which counters for different wind power output, short circuit current level and wind farm types. However, the presented researches have little consideration on LVRT control strategy for wind farm protection configuration and coordination.

\section{PMSG wind farm fault ride through feature based on LVRT control strategy}

3.1 LVRT methodology applied in PMSG

At present, there are three LVRT control methods used in PMSG, including reducing the generator side converter input power, eliminating the unbalanced power at the DC bus, and increasing the output power of the grid side converter. Although these methods can enhance wind farm LVRT capability, they all have noticeable shortcomings. For example, pitch angle control has slow response time and limiting the electromagnetic power of wind turbines leads to slow system recovery, discharging circuits have difficulty in heat dissipation and occupy large volumes, energy storage devices have high cost and complex control, reactive power compensation has slow response and limited capacity, and auxiliary circuits require large volumes and have high cost.

\subsection{An improved and comprehensive LVRT control strategy} Based on the structure characteristics of PMSG and without additional devices, a comprehensive LVRT scheme consisting variable resistance dumping circuit, reactive power control on the grid side and reactive power compensation is proposed in this paper, as shown in Fig. 1.

The control strategy of the variable resistance dumping circuit is

$$
\alpha=\frac{U_{d c}^{2}}{R_{d \max }\left(P_{g}-P_{s}\right)}
$$

where $\alpha$ is the resistance accommodation factor of the dumping circuit, whose value range is $(0,1] . U_{d c}$ is the converter DC bus voltage. $P_{g}$ and $P_{s}$ are the generator side input power and the grid side output power, respectively. $R_{d \max }$ is the maximum value of the dumping resistor, which can be calculated as:

$$
R_{d \max }=\frac{U_{d c \max }^{2}}{\Delta P_{\min }}
$$

where $U_{d c \max }$ is the maximum DC bus voltage of the converter, and $\Delta P_{\min }$ is the power difference between the generator and grid side when the dumping circuit is initiated to operate.

The dynamic reactive power control regulation is shown in Fig. 2, which changes the converter power factor to control its reactive power output based on different voltage dips. The power factor function can be obtained based on the wind turbine operation data.

The reactive power compensation device is formed of thyristor switched capacitors (TSC) in parallel with 


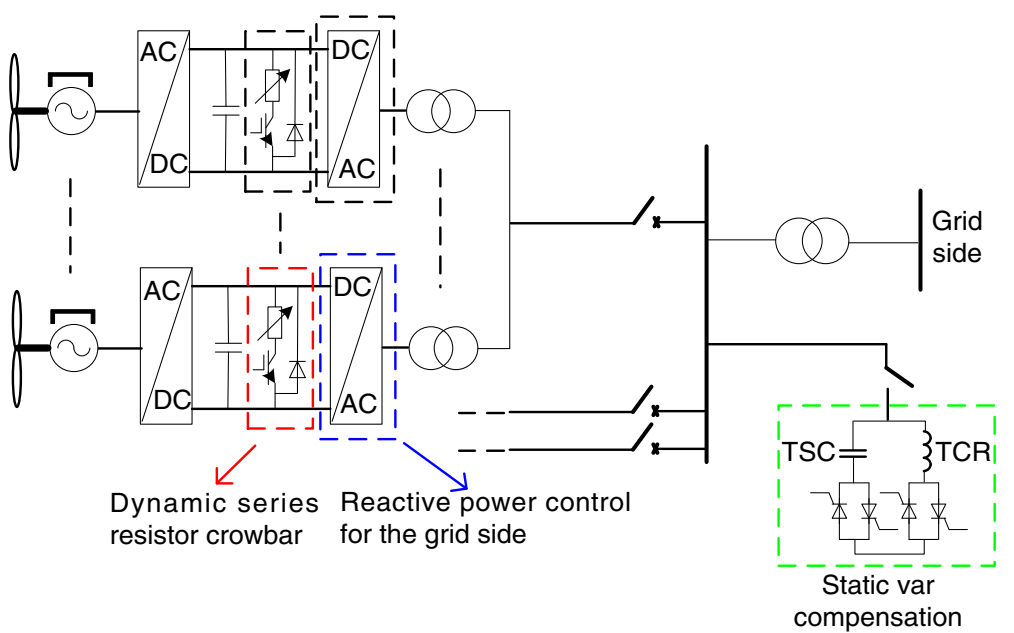

Fig. 1 Integrated control strategy for LVRT of PMSG

thyristor controlled reactors (TCR). The numbers of TSC and TCR installed can be modified according to the required reactive power compensation at certain voltage dip value and requirement to ensure grid voltage stability.

\subsection{Fault ride through characteristics of wind turbines with LVRT capability}

The wind farm considered consists of four 1.5 MW PMSGs and the reactive power compensation capacity is

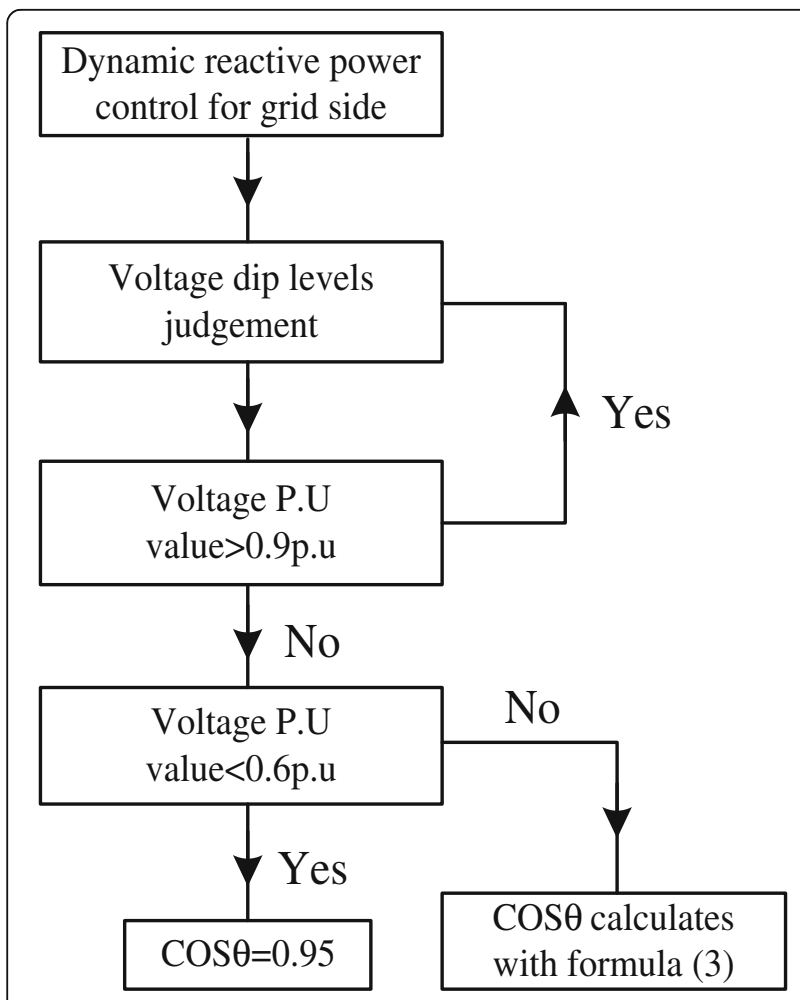

Fig. 2 Reactive power control strategy for grid side
1.5Mvar. When a three-phase fault with a duration of $0.1 \mathrm{~s}$ occurs on the high voltage side of the main wind farm transformer at $\mathrm{t}=2.0 \mathrm{~s}$, the output active/reactive power, the terminal voltage and current of the wind turbines are shown in Fig. 3. The simulation results show that: 1) The proposed LVRT method not only increases the wind farm LVRT capability but also improves the wind turbine stability after its LVRT; 2) The fault current has been significantly increased, up to 1.9 p.u., which can potentially adversely affect the protection operation and coordination as the current magnitude is usually used as the action criterion. Similar conclusions can be drawn for single phase-to-ground, two phase-toground and phase-to-phase faults.

\section{Protection configuration and coordination analysis of PMSG based wind farm}

4.1 Wind farm typical protection configuration and its coordination analysis

Figure 4 shows a typical protection configuration of a PMSG based wind farm in China, which references to the wind farm located in Dabancheng, Xinjiang, China. It has 33 LVRT enabled 1.5 MW PMSG wind turbines. All the wind turbines are connected to the grid through 3 collection lines with $35 / 110 \mathrm{kV}$ step-up transformers. Its equivalent impedance is shown in Fig. 5.

In order to analyze the protection coordination of the wind farm, the fault location is shown in Fig. 6. K1 to K9 represent wind farm internal faults and K10 represents the wind farm outgoing line fault.

\subsection{Wind turbine protection configurations based on the LVRT requirement}

Wind turbine protection mainly includes voltage protection, frequency protection, current protection zone I and III, and phase unbalance protection. The protection 


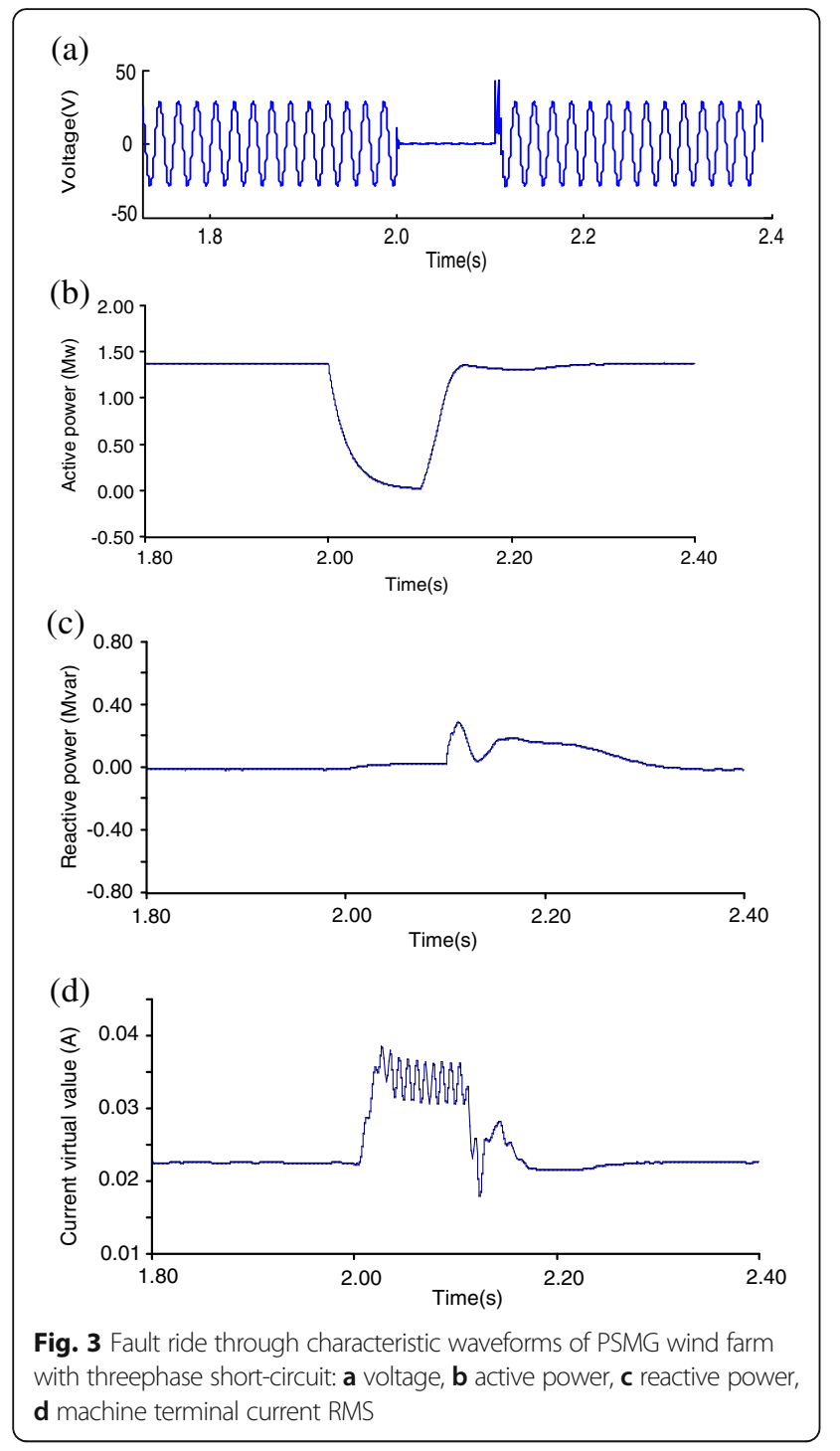

configuration before and after the improvement are compared in Table 1.

\subsection{Protection and coordination analysis of power collection line}

The protection of wind farm collection network mainly adopts three-section current protection, and its setting values are shown in Table 2.

At $1.5 \mathrm{~s}$, a three-phase short circuit fault with a duration of $1.2 \mathrm{~s}$ occurs at K1. The RMS currents of the 3 collection lines are shown in Fig. 7. The result shows that: (1) When the fault occurs, the wind turbine protection instantaneously opens the breaker at the low voltage side to cut G6 off; (2) Because the terminal voltage near wind turbine G6 is lower than 0.2p.u., G14, G15, G16, G17 and G21 are also tripped off instantaneously; (3) The current flowing through protection 1 is larger than its zone I setting value, so the fault is cut off. (4)The fuse cannot act instantaneously. (5)Although the current flowing into K1 from the non-fault collector network is less than its zone I setting value, it is larger than that of zone III. When the fault line current protection zone I fails to act, the protection zone III of the non-fault collector may act to trip all its connected wind turbines.

The simulation results show that, when the fault occurred at K1, it is designed to be cut off simultaneously by the breaker at the low voltage side of G6's transformer and the fuse at its high voltage side whereas the protection 1 is only considered as the backup protection of the fuse. However, as the fuse and protection 1 is not coordinated, a large numbers of wind turbines near G6 are falsely tripped off. At the same time, the current protection zone III of the non-faulted collectors may act and trip all the wind turbines, which is not in accordance to the stable

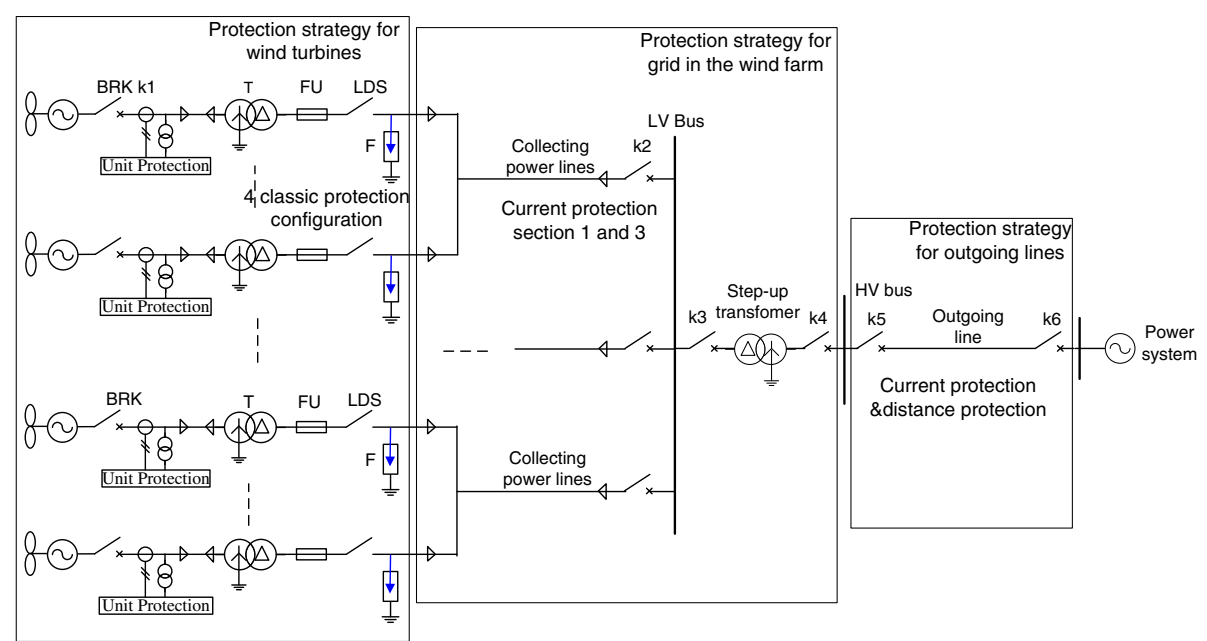

Fig. 4 Protection configuration for PSMG wind farm 


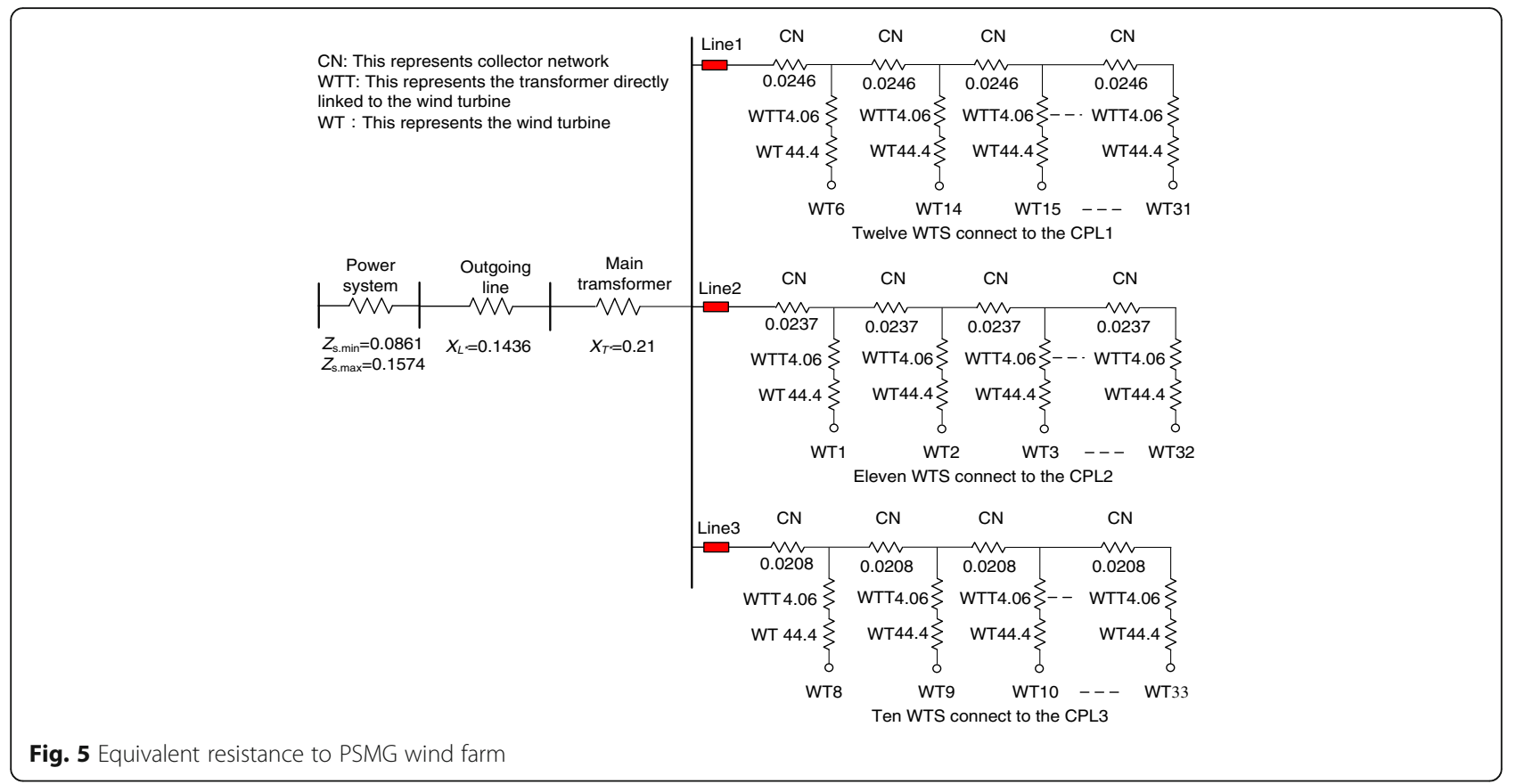

operation of the wind farm. The problems caused by a three-phase fault at K3 and $\mathrm{K} 5$ are similar.

Figure 8 shows the RMS current of the collector network when a three-phase fault occurs at $\mathrm{K} 2$ at $1.505 \mathrm{~s}$. The analysis shows that when the fault occurs, the protection zone I of collector line 1 can remove the fault instantaneously. However, there still exist two problems: (1)When the fault occurs at K2, the reverse current provided by the non-fault collector network is less than the setting value of the current protection zone I, but greater than that of the zone III. If the protection zone I of the fault collector line fails to operate, the protection zone III of the non-fault collector lines may act to trip off all the connected wind turbines. (2) When the fault is close to the bus of the collector network, the generator terminal voltage difference between the fault collector and the non-fault collector will be small, and low voltage protection of all the wind turbines will act immediately, leading to the disconnection of the whole wind farm. Problems caused by the fault at $\mathrm{K} 4$ and $\mathrm{K} 6$ are similar to the case of $\mathrm{K} 2$.

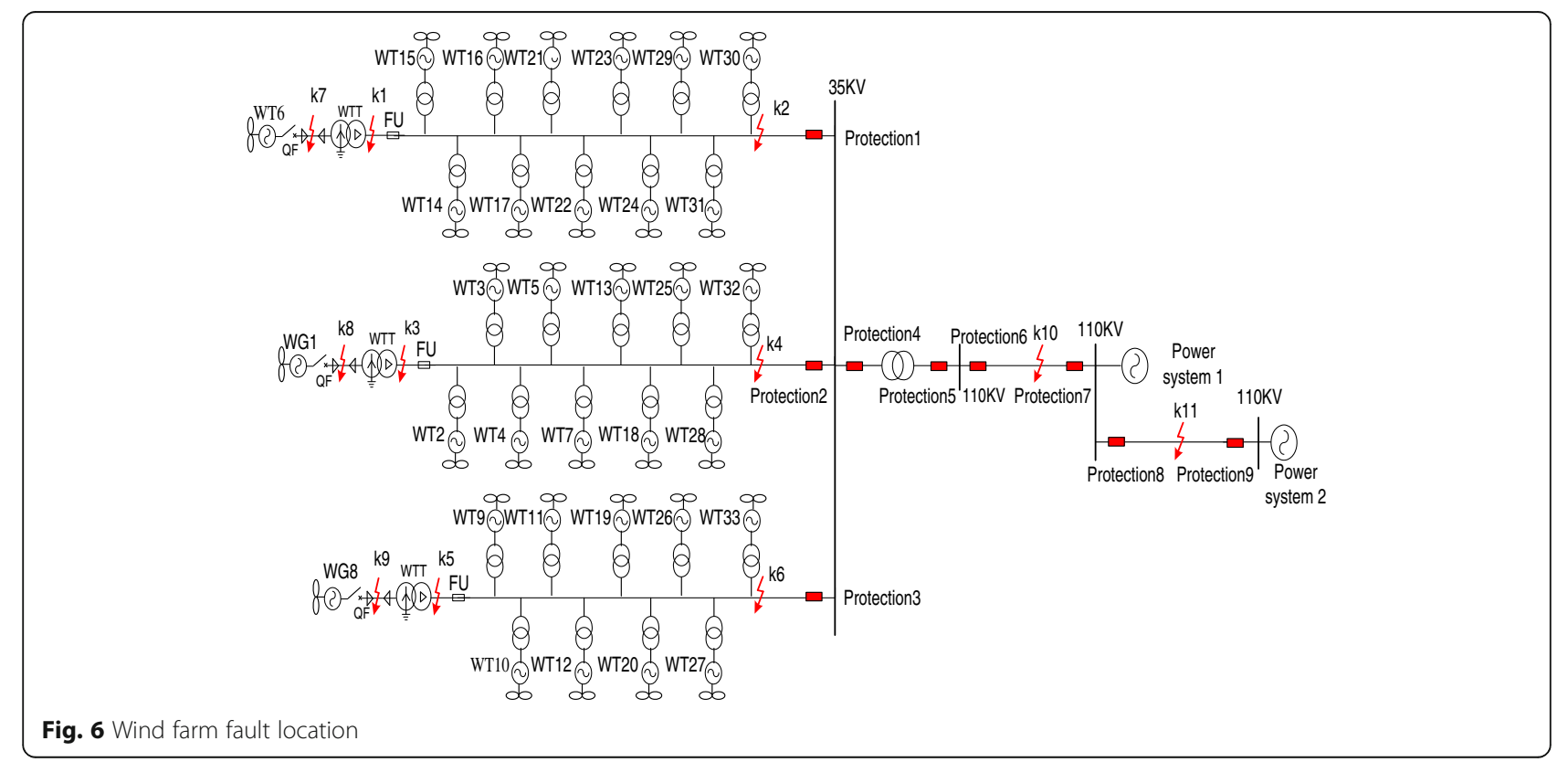


Table 1 Comparison between the conventional protection and improved protection

\begin{tabular}{|c|c|c|c|c|c|}
\hline \multirow[t]{2}{*}{ Protection } & & \multicolumn{2}{|l|}{ Without LVRT } & \multicolumn{2}{|l|}{ LVRT } \\
\hline & & Settings & Time(s) & Settings $\left(U_{N}\right)$ & Time(s) \\
\hline \multirow[t]{5}{*}{ Voltage violation protection } & Upper limit protection & $1.15 U_{N}$ & $0 \mathrm{~s}$ & $1.15 U_{N}$ & 0 \\
\hline & & $1.10 \cup_{N}$ & 0.1 & $1.10 U_{N}$ & 2 \\
\hline & Lower limit protection & $0.9 U_{N}$ & 0.1 & $0.9 U_{N}$ & 2.2 \\
\hline & & & & $0.5 U_{N}$ & 1.3 \\
\hline & & & & $0.2 U_{N}$ & 0.66 \\
\hline \multirow[t]{2}{*}{ Frequency protection } & Upper limit protection & $50.5 \mathrm{~Hz}$ & 0.1 & $52.5 \mathrm{~Hz}$ & 2 \\
\hline & Lower limit protection & $49.5 \mathrm{~Hz}$ & 0.1 & $47.5 \mathrm{~Hz}$ & 2 \\
\hline \multirow[t]{2}{*}{ Over current protection } & Primary section & Phase to phase fault & 0 & NO & \\
\hline & Zone III & $21_{N}$ & 1.5 & NO & \\
\hline Voltage unbalance protection & $0.1 U_{N}$ & & 0.3 & $0.1 U_{N}$ & 3 \\
\hline Current unbalance protection & $0.151_{N}$ & & 0.1 & $0.151_{N}$ & 1 \\
\hline
\end{tabular}

Table 5 shows the RMS current when a phase-toground fault occurres at $\mathrm{K} 1 \sim \mathrm{K} 6$. The analysis shows that when the fault happens, the currents flowing through protection $1 \sim 3$ are less than the setting values of their current protection of zone I, II and III. This will likely lead to over voltage and potentially cause the fault to become a phase-to-phase one resulting in the expansion of the accident. Thus, there requires some coordination in the collector network protection (Table 3).

Studies show that the wind farm protection coordination functions well when three-phase fault occurres at $\mathrm{K} 7, \mathrm{~K} 8$, and $\mathrm{K} 9$, which are all at the low voltage sides of the wind turbine transformers.

\subsection{Protection and its coordination analysis of outgoing line}

Based on Figs. 4 and 5, the protection of the wind farm outgoing lines includes the zero-sequence current protection and the distance protection. Their setting values are listed in Table 4.

Table 5 shows the maximum and minimum voltages of the wind turbines when a three-phase fault occurres at $\mathrm{K} 10$ of the outgoing line. The fault starts at $1.5 \mathrm{~s}$ and is cleared at $1.7 \mathrm{~s}$. The results show that: (1) After the fault occurres, the outgoing line's main protection will act within $0.1 \mathrm{~s}$; (2) All the currents flowing through the

Table 2 Three-section current protection setting of the collector network

\begin{tabular}{lllll}
\hline Collector network & & 1 & 2 & 3 \\
\hline Protection I & Current(A) & 1672 & 1800 & 1895 \\
& Time(s) & 0 & 0 & 0 \\
Protection II & Current(A) & 1117 & 1168 & 1252 \\
& Time(s) & 0.4 & 0.4 & 0.4 \\
Protection III & Current(A) & 440 & 400 & 370 \\
& Time(s) & 0.7 & 0.7 & 0.7 \\
\hline
\end{tabular}

collector protections (the protection 1 to 3 ) are smaller than their setting values. There is no bad coordination. (3) All the PMSG terminal voltages are larger than $0.2 \mathrm{pu}$, and thus the turbines will not trip. When a single phaseground fault occurs at the same place, similar conclusions can be drawn.

However, it needs to be noted that the generator minimum voltage is very close to 0.2 p.u. If the fault location is near the PCC (point of common coupling), the voltage will be lower than 0.2p.u. and the generator protection may act and potentially lead to the trip of the whole wind farm, which is not in accordance to wind farm operation and successful reclosure of the outgoing line. It will be beneficial for the stability of wind power integrated grid when the generator can last $0.3 \mathrm{~s}$ to $0.6 \mathrm{~s}$ at very low voltage. Meanwhile, because of the wind farm
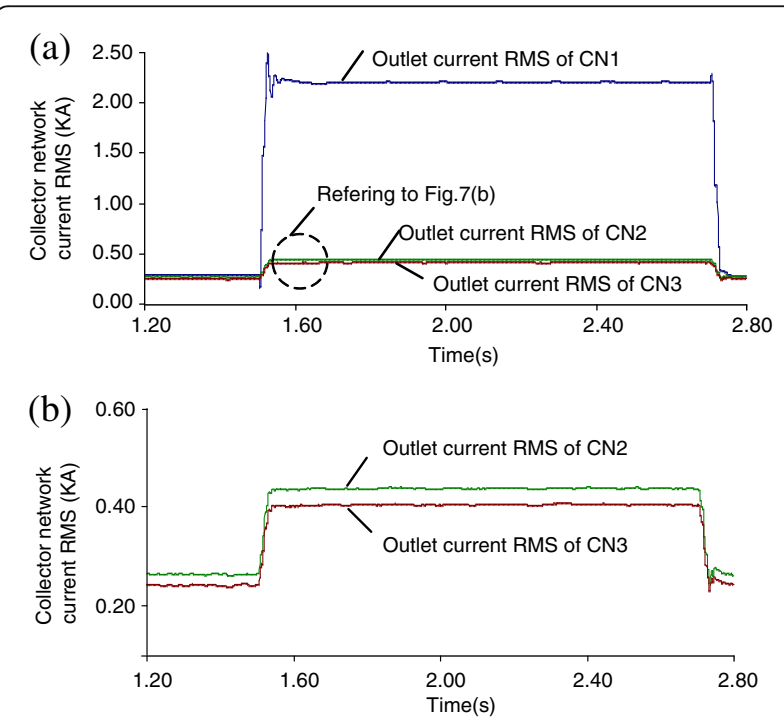

Fig. 7 a Collecting power lines current RMS waveforms for $k 1$ fault and b partial enlarged view 


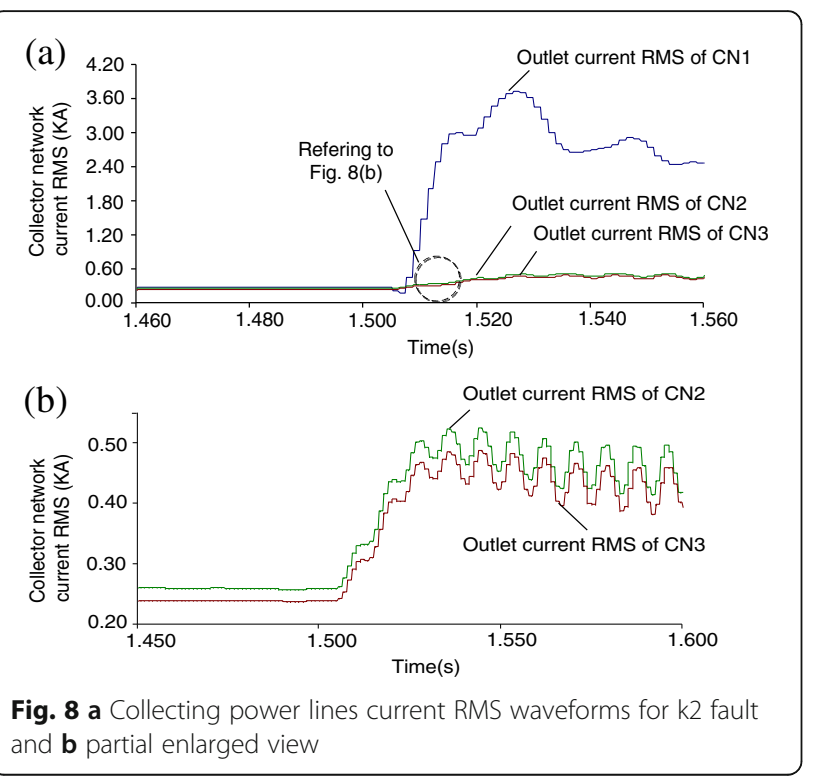

capacity accounted for only a smaller proportion of the power system, the positive sequence and negative sequence impedances of the wind farm are far greater than that of the grid. For the unique wind farm grounding mode, its zero sequence impedance is far less than the impedances of its positive and negative sequence. When the wind farm outgoing line has a single phase-toground fault, zero sequence current will become the main component and consequently, the three-phase fault currents tend to become similar indicating obvious weak power characteristic (the results of two phase-to-ground faults are similar). This will seriously affect the accuracy of the phase selection element as whose criterion is current overshoot.

\section{PMSG based wind farm protection coordination improvement scheme and its validation and analysis}

\subsection{Protection incoordination of PMSG wind farm with LVRT capability}

Based on the researches in Section 4, there are 4 main issues with protection incoordination of PMSG based

Table 3 RMS current of the collector network when singlephase faults occurres at K1 $\sim$ K6

\begin{tabular}{lllll}
\hline location & $\begin{array}{l}\text { Protection } \\
1(\mathrm{KA})\end{array}$ & $\begin{array}{l}\text { Protection } \\
2(\mathrm{KA})\end{array}$ & $\begin{array}{l}\text { Protection } \\
3(\mathrm{KA})\end{array}$ & $\begin{array}{l}\text { Section I } \\
\text { setting(A) }\end{array}$ \\
\hline k1 & 0.369 & - & - & 1700 \\
k2 & 0.341 & - & - & \\
k3 & - & 0.352 & - & 1800 \\
k4 & - & 0.331 & - & \\
k5 & - & - & 0.321 & 1900 \\
k6 & - & - & 0.313 & \\
\hline
\end{tabular}

Table 4 Setting values of outgoing line protection

\begin{tabular}{lllll}
\hline Protection type & & Section I & Section II & Section III \\
\hline Zero-sequence protection & Setting(A) & 1300 & 736 & 150 \\
& Time(s) & 0 & 0.4 & 0.7 \\
Distance protection & Setting( $(\Omega)$ & 15.193 & 32.735 & 56.1 \\
& Time(s) & 0 & 0.4 & 1.6 \\
\hline
\end{tabular}

wind farms with LVRT capability: (1) The current protection zone I for the collector network is in conflict with the fuse at the high voltage side of the turbine transformer; (2) The reduced reliability of the non-fault collector's current protection zone III; (3) The reduced reliability due to the incoordination between the collector current protection zone I and zone III; (4) The incoordination caused by wind farm's operation characteristics.

\subsection{Improvement for incoordination between collector} current protection zone I and fuse at high voltage side of turbine transformer

Considering the structural characteristic of PMSG, zero voltage ride through by combining the hardware and software can be realized. The fuse generally acts within $0.1 \mathrm{~s}$ and the generator has to last at least $0.1 \mathrm{~s}$ at voltage of 0.05 p.u. $\sim 0$. In order to realize the perfect match between the collector line current protection zone I and the fuse, a short time delay is added to the collector network current protection zone I. Figure 9 shows the improved action curve of the PMSG low voltage protection.

Furthermore, in order to solve the time incoordination problem between the collector protection I and the fuse, the difference of the fault occurred at the high voltage side of the turbine transformer and the collector line should be distinguished. The analysis shows that the fuse current for fault at transformer high voltage side is greater than the corresponding collector line protection setting value, and the current increases with the decrease of the distance from the fault point to the bus. On the contrary, when the fault occurs in the collector network, the fuse current is smaller than the protection setting value of the corresponding collector line and the current increases with the decrease of the distance from the fault point to the bus. Thus, the collector line current protection zone I setting values can be shown as below.

$$
\left\{\begin{array}{l}
\text { Main creterion : } U_{\text {measure }}<U_{\text {set }} \\
\text { the } 1 \text { st auxiliary creterion : } I_{\text {fuse }}>I_{\text {measure }}, t=\left(1+\frac{k \times U_{C} \times I_{N}}{U_{N} \times I_{C}}\right) t(I) s \\
\text { the } 2 \text { nd auxiliary creterion : } I_{\text {fuse }}>I_{\text {measure }} I_{\text {measure }}>I_{\text {set }}, t=0
\end{array}\right.
$$

The analysis shows that with the change of the fault location, the action time of the current protection zone I 
Table 5 Maximum and minimum voltages of the wind turbines connected to the collector network during a three-phase fault

\begin{tabular}{lcc}
\hline $\begin{array}{l}\text { Collecting power } \\
\text { line }\end{array}$ & $\begin{array}{c}\text { Maximum machine } \\
\text { terminal voltage(p.u) }\end{array}$ & $\begin{array}{c}\text { Minimum machine } \\
\text { terminal voltage(p.u) }\end{array}$ \\
\hline 1 & 0.296 & 0.220 \\
2 & 0.262 & 0.218 \\
3 & 0.261 & 0.217 \\
\hline
\end{tabular}

can be adjusted adaptively. To some extent, the LVRT capability can be improved when the fault location is closer to the bus. The smaller the protection time settings are, the quicker the fault can be removed. When the fuse is not reliable, as its back-up, the collector circuit protection with an inverse time-lag characteristic can remove the fault with a certain reliability and sensitivity.

\subsection{Coordination improvement of on-fault collector cir- cuits protection zone III}

A directional protective relaying is added to the collector network protection. When the current flows towards the bus direction, its output is " 0 ", otherwise, it is " 1 ". In order to avoid maloperation, the non-fault collector protection has the capability of locking itself by judging the current direction regardless the fault location.

\subsection{Coordination improvement between protection zone} I and zone III of fault collector circuits

The protection incoordination discussed here mainly shows that the single phase-to-ground fault current of the collector network is less than the setting values of its current protection zone I, II and III. The main reason is due to the lack of zero sequence current path in the collector network. In order to overcome this problem, grounding transformer and zero sequence current protection should be installed.

In this case, the grounding transformer capacity is $450 \mathrm{kVA}$ and its neutral grounding resistance is $20 \Omega$. The zero sequence current protection setting values of the respective wind farm collectors are 14.1A, 12.9A and $11.5 \mathrm{~A}$, (reliability coefficient is 1.5). Furthermore,

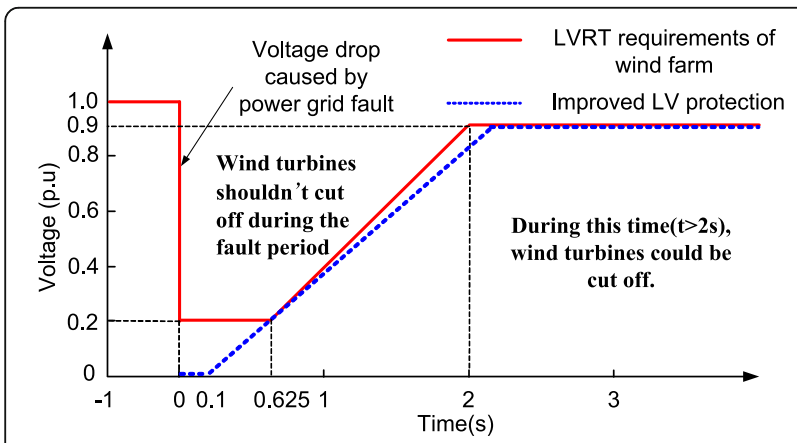

Fig. 9 the improvement low voltage motion curve of the PMSG the action time should be $0.7 \mathrm{~s}$, as same as the current protection zone III.

The waveforms in Fig. 10 show the difference between the former protection and the improved protection when a single phase-ground fault occurres in the collector 1 from $1.2 \mathrm{~s}$ to $1.5 \mathrm{~s}$. Based on the analysis, the incoordination problem of the network current protection zone I and III can be solved by the grounding transformer and zero sequence current protection configuration.

\subsection{Modification of protection incoordination caused by wind farm operating characteristics}

The protection incoordination here mainly refers to the inadequate time cooperation among the PMSG low voltage protection, collector protection and the fuse at the turbine transformer high voltage side. Therefore, it can be improved by modifying the generator protection action curve, as shown in Fig. 11.

The simulation results show that when a three-phase fault occurs at the collector outlets (K2, K4, and $\mathrm{K} 6$ in Fig. 6), the generator terminal voltage always exceeds 0.05p.u and the turbines can stay connected for at least $0.1 \mathrm{~s}$. These faults will be quickly isolated by the collector current protection whose action time is given in (3).

\section{Conclusion}

To tackle the existing coordination problem in PMSG based wind farms with LVRT capability, an improved wind farm protection coordination methodology is proposed. The proposed method adds a short time delay to the collector network current protection zone I to improve its coordination with the fuse at the high voltage side of the

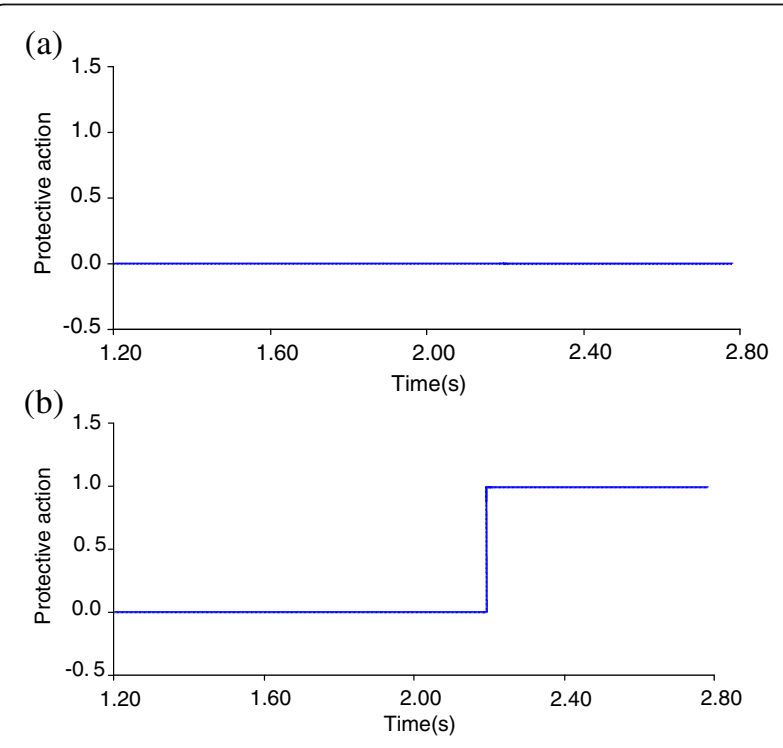

Fig. 10 a Common protective action $\mathbf{b}$ Improved protective action 


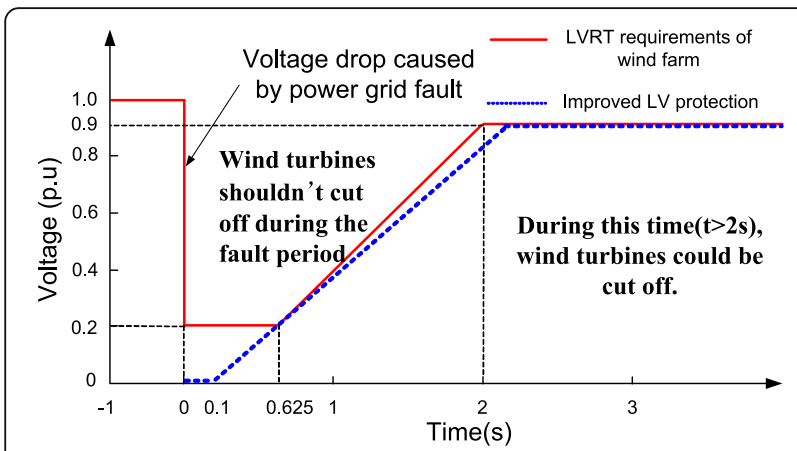

Fig. 11 Improved low voltage protection curve of PMSG

turbine transformer. Reliability improvement of the nonfault collector current protection zone III is achieved by introducing a directional protective relaying to the collector network protection, while reliability improvement of collector current protection zone I and zone III during single-phase faults are accomplished by installing grounding transformer and zero sequence current protection. Furthermore, improvement of low-voltage protection action is also achieved by modifying the generator protection action curve. Taking a PMSG based wind farm in Dabancheng, Xinjiang, China as an example, validity of the proposed method is verified.

Future work will investigate overvoltage problems caused by the turbine transformer winding breakdown, and the high voltage ride through method and protection incoordination modification potentially brought by this method.

\section{Authors' contributions}

All authors read and approved the final manuscript.

Received: 14 December 2016 Accepted: 9 May 2017

Published online: 24 July 2017

\section{References}

1. Zhou, W., Bi, D., Dai, Y., Cheng, L., \& Xiong, S. (2017). Design of VSG testbed for LVRT of renewable energy [J]. Electric Power Automation Equipment, $37(1), 107-111$.

2. Zhang, Y., Zheng, T. Q., Ma, L., et al. (2013). LVRT of photovoltaic gridconnected inverter adopting dual-loop control [J]. Transactions of China Electrotechnical Society, 28(12), 136-141.

3. Li, S., An, R., Xu, Z., et al. (2015). Coordinated LVRT of IG and PMSG in hybrid wind farm []]. Electric Power Automation Equipment, 35(2), 21-27.

4. Zhang, M., Li, N., \& Wang, Z. (2014). LVRT ability of PMSG wind power system []]. Electric Power Automation Equipment, 34(1), 128-134.

5. Zhang, X., Hu, M., Wu, Z., et al. (2014). Coordinated LVRT control of wind power generation system based on VSCHVDC [J]. Electric Power Automation Equipment, 34(3), 138-143.

6. Khatun MF and Sheikh MRI (2016) Low voltage ride through capability enhancement of DFIG-based wind turbine by a new topology of fault current limiter[C]//2016 2nd International Conference on Electrical, Computer \& Telecommunication Engineering (ICECTE), Rajshahi: pp. 1-5.

7. Carnielutti F, de Paris J, Massing JR, Pinheiro H, Tessele B (2016) A humanmachine interface applied for a low-voltage-ride-through test system for grid-connected wind turbines[C]//2016 12th IEEE International Conference on Industry Applications (INDUSCON). Curitiba: pp. 1-8.
8. Ananthababu, P., Trinadha, B., \& Ramcharan, K. (2009). Performance of dynamic voltage restorer (DVR) against voltage sags and swells using space vector PWM technique[C]/International Conference on Advances in Computing Control and Telecommunication Technologies (pp. 206-210). Karnataka: IEEE.

9. Abbey, C., \& Joos, G. (2007). Super capacitor energy storage for wind energy applications [J]. IEEE Transactions on Industry Applications, 43(3), 769-776.

10. Morren J, Pierik JG (2004) Voltage dips ride-through control of direct-drive wind turbines[C]//39th Inter-national UPEC. Bristol: 934-938.

11. Han, L., Li, F., Wang, C., Wang, H., \& Weiwei, C. H. E. N. (2016). A survey on impact of wind farm integration on relay protection [J]. Power System Protection and Control, 44(16), 163-169.

12. Zhang, B., Wang, J., Li, G., et al. (2012). Cooperation of relay protection for grid-connected wind power with low-voltage ride-through capability [J]. Electric Power Automation Equipment, 32(3), 1-6.

13. Heming, L., Dong, S., Wang, Y., et al. (2013). Coordinated control of active and reactive power of PMSG-basedwind turbines for low voltage ride through [J]. Transactions of China Electrotechnical Society, 28(5), 73-81.

14. Xiong, X., Zhang, H., \& Ouyang, J. (2011). Simulation analysis on transient output characteristics of DFIG with SVC [J]. Power System Protection and Control, 39(19), 89-93. 99.

15. Fan, X., Wang, W., Xie, Y., et al. (2016). Inverter Control Switching Between Grid-connected and Islanding Operating Modes of Permanent Magnet Wind Power Generation System in Low-voltage Microgrid [J]. Proceedings of the CSEE, 36(10), 2270-2783.

16. Zhao, Z., Wu, W., \& Wang, W. (2009). A Low Voltage Ride Through Technology for Direct-drive Wind Turbines Under Unbalanced Voltage Dips []]. Automation of Electric Power Systems, 33(21), 87-91.

17. $\mathrm{Hu}, \mathrm{S} ., \mathrm{Li}, \mathrm{J}$., \& Xu, H. (2007). Analysis on the Low- voltage-ride-through Capability of Direct-drive Permanent Magnetic Generator Wind Turbines [J]. Automation of Electric Power Systems, 31(17), 73-77.

18. Yao, J., Liao, Y., \& Zhuang, K. (2009). A Low Voltage Ride-through Control Strategy of Permanent Magnet Direct-driven Wind Turbine Under Grid Faults [J]. Automation of Electric Power Systems, 33(12), 91-96.

19. Lin, H., \& Chao, Q. (2010). Simulation study of modeling and control of direct drive wind turbine under grid fault [J]. Power System Protection and Control, 38(21), 189-195.

20. Yihui, S. H. I., Zongxiang, L. U., \& Yong, M. I. N. (2011). Practical Calculation Model of Three-phase Short-circuit Current for Doubly-fed Induction Generator [J]. Automation of Electric Power Systems, 35(8), 38-43.

21. Vicatos, M. S., \& Tegopoulos, J. A. (1991). Transient state analysis of a doublyfed induction generator under three phase short circuit [J]. IEEE Transactions on Energy Conversion, 6(1), 62-68.

22. Guan, H., Zhao, H., \& Liu, Y. (2008). Symmetrical short circuit analysis of wind turbine generator [J]. Electric Power Automation Equipment, 28(1), 61-64.

23. Kawady, T., Feltes, C., Erlich, l., et al. (2010). Protection system behavior of DFIG based wind farms for grid-faults with practical considerations [C]//IEEE Power and Energy Society General Meeting (pp. 1-6).

24. Morren, J., Pierik, J. T. G., \& de Haan, S. W. H. (2004). Voltage dip ride-through of direct-drive wind turbines[C]//Proceedings of 39th International Universities Power Engineering Conference (pp. 934-938).

25. Li, R., Gao, Q., \& Liu, W. (2011). Characteristics of direct-driven permanent magnet synchronous wind power generator under symmetrical three-phase short-circuit fault []]. Power System Technology, 35(10), 153-158.

26. Yang, G., Li, X., \& Zhou, Z. (2009). Impacts of Wind Farm on Relay Protection for Distribution Network and Its Countermeasures [J]. Power System Technology, 33(11), 87-91.

27. Comech, M. P., Montanes, M. A., \& Garcia, M. G. (2008). Overcurrent protection behavior before wind farm contribution[C]/The 14th IEEE Mediterranean Electro technical Conference, MELECON (pp. 762-767). Acacia: IEEE.

28. Yuling Wen (2009) Study about Wind Power Short Circuit and Impact on Power System Protection[D]. Xinjiang University

29. Su, C., Li, F., \& Wu, Y. (2011). An analysis on short-circuit characteristic of wind turbine driven doubly fed induction generator and its impact on relay setting [J]. Automation of Electric Power Systems, 35(6), 86-91.

30. Jang, S. I., Choi, J. H., Kim, J. W., et al. (2003). An adaptive relaying for the protection of a wind farm interconnected with distribution networks[C]// Proceedings of the IEEE Power Engineering Society Transmission and Distribution Conference (pp. 296-302). Dallas: IEEE.

31. Wen, Y., Chao, Q.. \& Tuerxun, Y. (2009). Study on adaptive protection of wind farm [J]. Power System Protection and Control, 37(5), 47-51. 